\title{
High-load anaerobic co-digestion of cheese whey and liquid fraction of dairy manure in a one-stage UASB process: limits in co-substrates ratio and organic loading rate
}

Carlos Rico ${ }^{\mathrm{a}, *}$, Noelia Muñoz ${ }^{\mathrm{b}}$, Josefa Fernández ${ }^{\mathrm{b}}$, José Luis Rico ${ }^{\mathrm{b}}$

${ }^{a}$ Department of Water and Environmental Science and Technologies, University of Cantabria, Avda. Los Castros, s/n, 39005, Santander, Spain

${ }^{b}$ Department of Chemical and Process Engineering Resources, University of Cantabria, Avda. Los Castros, s/n, 39005, Santander, Spain.

* Corresponding author. Tel.: +34 942201848; fax: +34 942201703.

E-mail address: ricoc@unican.es (Carlos Rico)

\begin{abstract}
Cheese whey is considered an important pollutant in dairy wastewaters and an environmental problem to solve. This study aimed to develop a treatment process that combines the advantages of co-digesting cheese whey with manure and the short hydraulic retention time of a high-load anaerobic treatment system by using liquid fractions of dairy manure as a co-substrate. The proposed co-digestion process consists of a one-stage UASB reactor with an external settler and effluent recycling for alkalinity supplementation. Under a constant hydraulic retention time of 2.2 days and increasing proportion of cheese whey in the feed, the system demonstrated stable operation up to a $75 \%$ cheese whey fraction in the feed, with an applied organic loading rate of $19.4 \mathrm{~kg} \mathrm{COD} \mathrm{m}^{-3} \mathrm{~d}^{-1}$, obtaining a 94.7\% COD removal and a volumetric methane production rate of $6.4 \mathrm{~m}^{3} \mathrm{CH}_{4} \mathrm{~m}^{-3} \mathrm{~d}^{-1}$. Critical biomass washout was experienced when the cheese whey fraction in the feed was $85 \%$. Operation at a constant $60 \%$ cheese whey fraction in the feed mixture enabled stable operation under an organic loading rate of $28.7 \mathrm{~kg}$ COD $\mathrm{m}^{-3} \mathrm{~d}^{-1}$ and 1.3 days HRT, with 95.1\% COD removal and a volumetric methane production rate of $9.5 \mathrm{~m}^{3}$ $\mathrm{CH}_{4} \mathrm{~m}^{-3} \mathrm{~d}^{-1}$. This new high-load co-digestion method proposed is a promising solution for areas where cheese factories and intensive livestock farming are responsible for environmental pollution caused by unsuitable cheese whey and manure management practices.
\end{abstract}

\section{Keywords}

UASB; cheese whey; co-digestion; manure liquid fraction; methane 


\section{Introduction}

Cheese whey is the watery part of milk that is separated from the curd in the cheesemaking process. It is the major by-product of dairy industries, and due to its high organic load, it has a strong polluting potential, causing an excess of oxygen consumption if it is directly disposed of in water bodies. Moreover, cheese whey can cause impermeabilization, eutrophication, toxicity, and other conditions in the receiving environments [1]. Typically, cheese whey has 5-8\% total solids (TS) containing approximately $10-20 \%$ proteins, $60-80 \%$ lactose and the remaining minerals, vitamins, fat, lactic acid and trace elements [2]. Generally, cheese whey presents a high organic load (up to $80 \mathrm{~g} \mathrm{COD} \mathrm{L}^{-1}$ ), a low alkalinity content (<2500 mg $\mathrm{CaCO}_{3} \mathrm{~L}^{-1}$ ) and very high biodegradability [3].

In the past, most cheese factories disposed their effluents by land application or direct discharge to receiving waters $[1,4]$. Several biological and physicochemical valueadding processes have been reported for whey exploitation over the last decades [5-9]. However, due to economic convenience, small and medium-sized cheese producing units usually have neither treatment facilities to recover valuable constituents nor wastewater treatment systems for the appropriate disposal of whey. Cheese whey is considered the most important pollutant in dairy wastewaters, not only for the high organic load, but also for the volume generated [10]. For instance, for the production of $1 \mathrm{~kg}$ of cheese, $10 \mathrm{~kg}$ of milk is needed, originating $9 \mathrm{~kg}$ of cheese whey [1]. Approximately half of the 115 million tons of whey produced world-wide every year are disposed of on land or in bodies of water [11]. In Cantabria, a small region located in northern Spain, only $42.6 \%$ of 15,600 tons per year of cheese whey produced in the region were properly managed in 2005, mainly as animal feed [12]. In 2011, 16,900 tons of cheese whey were produced in Cantabria with similar management strategies. 
This situation justifies the development of treatment methods for this waste stream.

Because whey has a high chemical oxygen demand and a very high biodegradability, anaerobic treatment is the most suitable biological method for treating or pre-treating this waste effluent [13]. Instead of requiring a large amount of energy to be treated in an aerobic wastewater process, whey produced in dairy industries can produce energy that can itself be used for heat and electricity generation. In this regard Spachos and Stamatis [14] performed an exergetic and economic analysis of an anaerobic treatment system of whey accompanied by the production of steam, concluding that the anaerobic treatment of whey can be a sustainable investment, at least for a substantial volume of whey. The anaerobic treatment of cheese whey has been well reported by several authors under different systems and conditions, mainly in high-rate anaerobic systems, such as the upflow anaerobic sludge blanket (UASB) reactor [11,15-24].

In spite of its high biodegradability, cheese whey is quite a problematic substrate for being treated by anaerobic processes due to its lack of alkalinity [16]. Because the organic matter is in a soluble form, the rate-limiting step is the methanogenic step. This limit implies the possibility of accumulating volatile fatty acids (VFA) that can exhaust the buffering capacity, leading to acidification and reactor failure, especially in highload reactors. This problem can be solved by working with diluted whey, which is much simpler to treat $[16,23]$, or by adding alkalinity to the system. Two-stage treatment processes can also result in a safer operation, reducing the risk of acidification [23]. Diamantis et al. [24] developed a two-stage CSTR-UASB system without any requirements for alkali consumption for the anaerobic treatment of diluted cheese whey with dairy-washing waters.

Another drawback for the anaerobic treatment of cheese whey in high-load systems is that biomass granulation is hindered and there is a tendency to produce an excess of 
viscous exopolymeric materials that severely reduce sludge settleability, which can lead to biomass washout [16]. Passeggi et al. [25] studied a modified UASB reactor that included a scum extraction device and an external settler as an alternative to the anaerobic treatment of dairy wastewaters. Furthermore, some authors reported supplementation with external nutrients to maintain system stability $[23,26]$.

To address the above difficulties, the co-digestion of whey with animal manure in a CSTR digester has proven to be a solution because manure can provide the necessary nutrients and the buffer capacity to ensure the stability of the process [13,27-29]. In addition, using biogas from the co-digestion of animal manure and suitable organic substrates is also a very attractive solution from a socio-economic point of view, when biogas externalities, including environmental, human and animal health benefits, are quantified and integrated in the overall economic benefit [30]. However, the anaerobic co-digestion of cheese whey with animal manure has traditionally required the use of CSTR digestion systems due to the high suspended solids content of animal manure, precluding the use of high-load anaerobic reactor systems that operate with lower hydraulic retention time (HRT) and smaller reactor size. Furthermore, another drawback for CSTR digesters is the requirement of mixing devices.

Cantabria has a bovine population of approximately 280,000 AU (mainly dairy), a humid climate and pronounced slopes that makes the liquid fraction of manure responsible for surface and groundwater pollution. These environmental problems are difficult to solve due to the high contents of organic matter and nutrients. In this regard, Rico et al. [31] developed a procedure to separate the liquid and solid fractions of dairy manure with the aim of obtaining a liquid fraction whose characteristics allow anaerobic digestion treatment in high-load anaerobic systems. The main characteristics of the separated liquid fraction were an anaerobic biodegradability higher than $80 \%$ and the 
absence of suspended solids which are very good characteristics for high load anaerobic reactors, such as the UASB. These characteristics could also allow anaerobic codigestion treatment with cheese whey in high-load anaerobic systems.

The overall objective of the study was to develop a stable one-phase mesophilic codigestion process in a UASB reactor, for a mixture consisting of cheese whey and a liquid fraction of dairy manure, without external alkalinity or nutrient supplementation. Given that granulation does not occur with this type of wastewater and that some solids can be lost with the effluent, an external settler was placed in the UASB reactor discharge to enhance the reactor performance. In the present investigation, the performance and the limits of the proposed treatment process have been analysed. The cheese whey fraction in the feed, the HRT, the organic loading rate (OLR) and the biomass washout have been evaluated.

\section{Materials and methods}

\subsection{Substrates}

Cheese whey (CW) was supplied by Queserías la Fuente, a dairy milk processor located in Heras (Cantabria, Spain). Once a month the CW was transported to the laboratory and stored at $4^{\circ} \mathrm{C}$ prior to use. The $\mathrm{CW}$ characteristics (see Table 1) were quite uniform during the experimentation as indicated by the relative low SD in CW characteristics.

The liquid fraction of dairy manure used as a co-substrate was obtained from a pilot plant located in the agricultural secondary school 'La Granja” (Heras, Cantabria) using the procedure reported by Rico et al. [31]. Dairy manure was collected from the manure pit of a 500-free stall dairy cow farm equipped with scrape systems. Manure was extracted from the dung pit by a tractor equipped with a vacuum tank system and transported to the pilot plant. 
Raw manure was separated by means of a screw press separator (Doda MS5CE, $0.8 \mathrm{~mm}$ mesh). Then, the screened liquid fraction (SLF) was subjected to decanter centrifuge separation (Pieralisi Baby 2) operating at 5200 rpm to obtain the screened flocculated centrifuged liquid fraction (SFCLF) used in the present work. Centrifugation was enhanced by chemical reagents which were mixed with the screened liquid manure in a labyrinth-pipe section adapted as a static mixer. $\mathrm{FeCl}_{3}\left(50 \mathrm{~g} \mathrm{~L}^{-1}\right)$ was used as a coagulant (dose $2 \%$ - TS base) and a cationic polyacrilamide $\left(4 \mathrm{~g} \mathrm{~L}^{-1}\right)$ was used as a flocculant (dose 1.5\% - TS base). Once a month the SFCLF was processed and collected from the pilot plant, delivered to lab installations and stored at $4^{\circ} \mathrm{C}$ prior to use. SFCLF characteristics were not uniform due to the manure pit management and weather conditions but reasonably consistent during the experiment period to ensure the reliability of the experiments. The mean characteristics of both substrates during experimentation are shown in Table 1.

\subsection{Experimental setup scheme}

The experimental setup scheme of the process developed is shown in Fig. 1. Manure separation processes to obtain SFCLF were carried out at the pilot scale. More details about the pilot installation and the separation processes can be found in Rico et al. [32]. The UASB reactor was operated at lab scale.

\subsection{UASB reactor}

The UASB reactor was cylindrical, made of PVC, $9.7 \mathrm{~cm}$ in internal diameter and 150 cm high with an operating volume of $8 \mathrm{~L}$. In the upper part, there was a gas-liquid-solid separator device similar to those described in the literature for UASB reactors [33]. The 
feed came into the lower zone and the effluent left the reactor by means of an exit tube at the top of the reactor.

An external settler with an operating volume of $3.2 \mathrm{~L}$ was placed in the UASB reactor discharge to enhance reactor performance. The settler consisted of a cylindrical PVC tank, $7.7 \mathrm{~cm}$ in internal diameter and $100 \mathrm{~cm}$ high, with a conical bottom. The function of the settler was to obtain a final anaerobic effluent free of suspended solids and to avoid obstructions in the effluent recycle pipe. The clarified effluent was recirculated into the reactor to provide bicarbonate alkalinity to the system.

A stable reactor temperature was maintained at $35^{\circ} \mathrm{C}$ in the UASB reactor by means of an electric heating blanket.

Biogas left the reactor through the gas collector by its own pressure. The volume of biogas generated in the UASB reactor was measured by means of a home-made biogas meter device constructed using two coaxial chambers made of acrylic cylinders which were interconnected by means of two small holes in the lower zone of the internal chamber. The internal chamber was closed on the top arranged with a piping connection to a three-way solenoid valve with biogas from the UASB reactor inlet and exhaust. A pre-set magnetic level sensor regulated the operation of the three-way valve in order to release the collected biogas, resetting the whole system. The total volume of biogas is the product of multiplying the number of cycles (fillings or emptyings) which were recorded by a counter system, times the volume of the chamber.

The UASB reactor was inoculated with $5 \mathrm{~kg}$ of biomass (43.1 $\mathrm{g} \mathrm{VSS} \mathrm{kg}{ }^{-1}$ ) collected from a pilot UASB reactor that had been processing the SFCLF of dairy manure at $35^{\circ} \mathrm{C}$. This inoculum was originally obtained by decanter centrifuge separation of the digested SLF of dairy manure. The solid fraction separated was used as an inoculum. 


\subsection{Mode of operation}

The UASB reactor was fed in continuous-mode operation. The HRT was calculated for the UASB reactor alone by dividing the operating volume of the UASB reactor by the influent flow rate. Both substrates were mixed and fed to the reactor by a peristaltic pump. The duration of the UASB experiment was 210 days, and the experimentation was divided in two stages.

The feed ratios were changed after 9-11 days of operation (depending on the HRT) at the current loading. For each operating condition, influent and effluent samples were collected, and their characteristics were determined during five consecutive days after stationary conditions were reached. Steady state was reached when the operation conditions were maintained for three HRTs and the reactor showed stability. The influent, effluent and biogas samples were analysed immediately after sampling. The UASB operation values showed in tables and figures are the mean values \pm SD of the five mean values obtained (duplicate analyses) after steady state conditions were reached.

Based on previous unpublished experiences with diluted cheese, during the first experimentation stage, the HRT of the UASB reactor was set to 2.2 days. Starting from a substrate mixture ratio of 10:90 (v/v CW:SFCLF), the CW fraction was progressively increased by $5 \%$ up to 55\%. From 55\%, the CW fraction was increased by $10 \%$ until the reactor limits were reached in terms of CW ratio. Operation at a constant HRT lasted 140 days. The recirculation to feed volume ratio was 3:1 during the first stage.

After this period, a second experimentation stage was performed, in which the CW ratio in the feed was set at $60 \%$ and the HRT was progressively reduced starting from 2.2 
days to check the limits in terms of the HRT and the OLR. During the second stage, recirculation flow was maintained. Consequently, the recirculation-to-feed ratio was gradually reduced during second stage.

The parameters analysed were $\mathrm{pH}$, alkalinity, $\mathrm{TS}$, VS, total COD $\left(\mathrm{COD}_{\mathrm{T}}\right)$, filtered COD $\left(\mathrm{COD}_{\mathrm{f}}\right)$, COD due to volatile fatty acids $\left(\mathrm{COD}_{\mathrm{VFA}}\right)$, Kjeldahl nitrogen $(\mathrm{TKN}-\mathrm{N})$ and total phosphorus $\left(\mathrm{P}_{\mathrm{T}}\right)$. The volume of biogas produced and methane content of the biogas were determined daily. Solids from the settler were withdrawn after each experimental condition to determine the losses of biomass from the UASB caused by washout.

\subsection{Analytical techniques}

Volatile fatty acids (VFAs) were determined using a HP6890 gas chromatograph (GC) fitted with a 2 m 1/8-in glass column, liquid phase 10\% AT 1000, packed with the solidsupport Chromosorb W-AW 80/100 mesh. Nitrogen was used as the carrier gas at a flow rate of $14 \mathrm{~mL} / \mathrm{min}$, and a FID detector was installed. The VFA concentrations are expressed in COD units. The Biogas composition was assayed on a $2 \mathrm{~m}$ Poropak T column in a HP 6890 GC system with helium as the carrier gas at a flow rate of 15 $\mathrm{mL} / \mathrm{min}$ with a TCD detector. The biogas and methane volumes are expressed at $0^{\circ} \mathrm{C}$ and $1 \mathrm{~atm}$. The influent and effluent pHs were measured from samples with a glass electrode $\mathrm{pH}$ meter (WTW, SENTIX 21). The bicarbonate alkalinity (BA) and the volatile acids alkalinity (VAA) were determined by titration at $\mathrm{pH}$ of 5.1 and 3.5, respectively, according to the method described by Anderson and Yang [34]. $0.45 \mu \mathrm{m}$ filters were used for $\mathrm{COD}_{\mathrm{f}}$ determination. All of the other analyses were performed according to standard methods [35]. All of the analyses were performed in duplicate 
rather than in triplicate because they were quite homogeneous samples.

\section{Results and discussion}

\subsection{UASB start-up process}

The start-up of UASB reactors is a complicated process that requires acclimatization and the growth of the sludge bed. In this work, the UASB was easy to start-up because the UASB was inoculated with biomass from another UASB that had been operating with a SFCLF. The reactor was filled with $5000 \mathrm{~g}$ of inoculum (215.5 $\mathrm{g}$ VSS $\left._{\text {inoculum }}\right)$ and $6 \mathrm{~L}$ of an initial feed mixture containing 90\% SFCLF and 10\% CW. Subsequently it was operated in batch mode until biogas production ceased and the VFAs were completely removed in the liquid phase. Then, the UASB started to be fed with $10 \% \mathrm{CW}$ in the feed mixture at an HRT of 2.2 days.

\subsection{Operation at a constant HRT (2.2 days)}

The data in Table 1 reveal that the $\mathrm{CW}$ had quite a higher organic content than the SFCLF. The characteristics of the UASB influents and effluents during this stage are given in Table 2. As expected, some parameters in the influent showed a significant correlation with the CW content in the feed: $\mathrm{COD}_{\mathrm{T}}, \mathrm{COD}_{\mathrm{f}}$, TS, and VS $(\mathrm{p}<0.01)$. The lowest values for these parameters were determined for the mixture feed consisting of $10 \% \mathrm{CW}$ and $90 \%$ SFCLF with $14.7 \pm 2.4,13.5 \pm 2.2,15.0 \pm 0.3$ and $9.2 \pm 0.2 \mathrm{~g} \mathrm{~L}^{-1}$ for $\mathrm{COD}_{\mathrm{T}}, \mathrm{COD}_{\mathrm{f}}$, TS and VS, respectively. These concentrations increased up to $45.4 \pm$ 3.7, $40.2 \pm 1.3,47.3 \pm 1.1$ and $41.6 \pm 1.0 \mathrm{~g} \mathrm{~L}^{-1}$, respectively, for the mixture feed containing $85 \% \mathrm{CW}$. As a result of this increase, with increasing the $\mathrm{CW}$ content in the feed, the OLR applied to the UASB also increased. This trend was true for all of the 
conditions except for the changes from $15 \%$ to $20 \% \mathrm{CW}$ and $45 \%$ to $50 \% \mathrm{CW}$, when the COD of the feed mixture diminished. It must be taken into account that the characteristics of the SFCLF were not constant, and for this reason the OLR applied with CW contents in the feed of $20 \%$ and $50 \%$ were slightly lower than those with $15 \%$ and 45\% CW, respectively. Moreover, whereas the anaerobic biodegradability of the CW is close to $100 \%$, a small part of SFCLF COD is recalcitrant [31]. For this reason, higher CW content in the feed led to the higher biodegradability of the mixture as well. In contrast, the $\mathrm{pH}$, alkalinity (BA and VAA) and $\mathrm{COD}_{\mathrm{VFA}}$ did not show significant correlations with the $\mathrm{CW}$ content in the mixture. For instance, the $\mathrm{pH}$ in the influent varied from $5.9 \pm 0.3(30 \% \mathrm{CW})$ to $6.6 \pm 0.3(45 \% \mathrm{CW})$.

The low bicarbonate alkalinity in the influent, lower than 20 meq $\mathrm{L}^{-1}$ for all of the experimental conditions, is problematic for the anaerobic process, leading to acidification and a drop in $\mathrm{pH}$ that would inhibit the process, causing failure of the UASB reactor. As reported in the Materials and Methods section, effluent recirculation was used to address this problem. As Table 2 shows, the bicarbonate alkalinity in the effluent was between 145 and 189 meq $\mathrm{L}^{-1}$, sufficient for the process.

The effluent characteristics in Table 2 show a stable, high-efficiency UASB reactor operation for all the experimental conditions. The OLR was progressively increased from $6.8 \mathrm{~kg}^{\mathrm{COD}} \mathrm{T}_{\mathrm{T}}^{-3} \mathrm{~d}^{-1}$ for $10 \% \mathrm{CW}$ content in the feed to $20.9 \mathrm{~kg} \mathrm{COD}_{\mathrm{T}} \mathrm{m}^{-3} \mathrm{~d}^{-}$ ${ }^{1}$ when the CW content was $85 \%$. The effluent $\mathrm{pH}$ remained in a range between 7.8 and 8.2, except for the last condition (85\% CW), when it dropped to 7.6.

The process achieved $\mathrm{COD}_{\mathrm{T}}$ removal percentages higher than $94 \%$. Only for the first condition (10\% CW) was the removal percentage of $\mathrm{COD}_{\mathrm{T}}$ lower than $94 \%(91.2 \%)$. This result may be attributed to the lower biodegradability of the mixture feed and to the fact that it was the first condition after start-up. Effluent $\mathrm{COD}_{\mathrm{T}}$ concentrations ranged 
between 0.9 and $1.5 \mathrm{~g} \mathrm{~L}^{-1}$, except for the last condition (85\% CW), when the mean effluent $\mathrm{COD}_{\mathrm{T}}$ was $2.3 \pm 1.8 \mathrm{~g} \mathrm{~L}^{-1}$. The highest $\mathrm{COD}_{\mathrm{T}}$ removal percentages (97.4\%) were observed for $65 \%$ and $75 \% \mathrm{CW}$ contents in the feed due to the higher biodegradability of the mixture feed.

The efficiency of the system decreased when the CW ratio in the feed was $85 \%$, not only in terms of the COD removal efficiency but also in stability, as will be reported below. Despite stability problems detected with $85 \% \mathrm{CW}$ in the feed, the organic removal rate $(\mathrm{ORR})$ exhibited a strong Pearson correlation $(\mathrm{p}<0.001)$ with the OLR applied for all the conditions tested, as can be observed in Fig. 2a. The removal percentage of $\mathrm{COD}_{\mathrm{f}}$ was always higher than the removal percentage of $\mathrm{COD}_{\mathrm{T}}$.

VFAs were not present in the effluent until stability problems arose when the UASB was started to be fed with the mixture containing $85 \% \mathrm{CW}$. At this point, VFAs were detected in the effluent. After changing the feed mixture from $75 \%$ to $85 \% \mathrm{CW}$, the system was able to operate during some days, but when steady state was reached, the UASB efficiency started to decrease due to biomass washout. In fact, after three days of data collection operating with $85 \% \mathrm{CW}$ in the mix, critical scum layer formation and biomass flotation were observed. The gas collector and effluent discharge were blocked by scum and solids and operation was stopped. This blockage is the reason for the high standard deviation of effluent parameters for this condition.

The volumetric methane production rate exhibited a strong Pearson correlation $(\mathrm{p}<0.001)$ with OLR (Fig. 2b). The UASB yielded $2.1 \pm 0.2 \mathrm{~m}^{3} \mathrm{CH}_{4} \mathrm{~m}^{-3} \mathrm{~d}^{-1}$ when the CW fraction in the feed was $10 \%$. This rate increased progressively with the CW:SFCLF ratio in the feed, reaching its highest value for $85 \% \mathrm{CW}, 7.0 \pm 0.2 \mathrm{~m}^{3} \mathrm{CH}_{4}$ $\mathrm{m}^{-3} \mathrm{~d}^{-1}$. Specific methane yields ranged between 0.31 and $0.34 \mathrm{~L} \mathrm{CH}_{4} \mathrm{~g}^{-1} \mathrm{COD}$, showing very good performance of the system. The lowest value $\left(0.31 \mathrm{~L} \mathrm{CH}_{4} \mathrm{~g}^{-1} \mathrm{COD}\right)$ was 
observed for the first condition (10\% CW), which is in accordance with the lowest COD removal percentage. Again, the methane content in the biogas diminished with increasing CW content in the feed (Fig. 2b). In this case, a negative Pearson correlation was observed between the methane content in the biogas and the OLR $(\mathrm{p}<0.05)$. Under the first condition, $10 \% \mathrm{CW}$ fraction in the feed, the methane content in the biogas was $70.1 \pm 0.3 \%$. For the last condition, $85 \% \mathrm{CW}$ in the feed, the methane content in the biogas was $53.0 \pm 1.1 \%$. In the specific context of this work, this result can be attributed to two factors: the OLR and the difference in organic compounds between the CW and the SFCLF. On one hand, as the OLR increases, more carbon dioxide is produced per unit of volume of the liquid phase, which can saturate the liquid phase with $\mathrm{CO}_{2}$. As a result, a higher portion of the produced $\mathrm{CO}_{2}$ is released in the gas phase, reducing the percentage of $\mathrm{CH}_{4}$ in the biogas. On the other hand, as shown in Table 1, whereas more than $50 \%$ of the COD in the SFCLF was due to VFAs, no VFAs were observed in the

CW. The organic compounds in the CW must be processed by various groups of microorganisms, and as a consequence, higher CW:SFCLF ratios in the feed resulted in a higher $\mathrm{CO}_{2}$ content in the produced biogas. In this sense, the effluent $\mathrm{pH}$ did not vary as a function of the OLR, as the data in Table 2 show. The effluent $\mathrm{pH}$ values varied between 8.2 and 7.8 for all of the conditions except for the $85 \% \mathrm{CW}$ ratio, when the effluent $\mathrm{pH}$ was 7.6. The methane content decrease in the biogas cannot be attributed to the effluent $\mathrm{pH}$ because there is no significant correlation between the OLR and the effluent $\mathrm{pH}$.

\subsection{Operation at constant CW:SFCLF ratio (60:40) and decreasing HRT}

After reaching the CW:SFCLF ratio operating limit at a constant HRT of 2.2 days, a new limit was investigated. The UASB was fed with a mixture consisting of $60 \% \mathrm{CW}$ 
and $40 \%$ SFCLF. The operation started with an initial HRT of 2.2 days. The HRT was gradually decreased until a drop in efficiency was observed. The HRTs applied were 2.20, 1.80, 1.65, 1.45, 1.30 and 1.18 days, which were conditioned by the feeding pump capacity. In this case, as the feed characteristics were quite similar, decreases in the HRT were accompanied by increases in the OLR. The characteristics of the UASB influents and effluents during this stage are given in Table 3. The OLR applied during this experimental period varied within the range 16.3-30.5 $\mathrm{kg} \mathrm{COD}_{\mathrm{T}} \mathrm{m}^{-3} \mathrm{~d}^{-1}$, which is an OLR 46.9\% higher than the maximum OLR applied during the previous period.

The data in Table 3 show the good performance of the system. The $\mathrm{COD}_{\mathrm{T}}$ removal percentage remained over 93\% for all the conditions except for the 1.18 day HRT, when a removal percentage of $88.3 \%$ was obtained. VFAs in the effluent were detected from the 1.65 day HRT, but remained at low values $\left(<0.5 \mathrm{~g} \mathrm{COD}_{\mathrm{VFA}} \mathrm{L}^{-1}\right)$ during operation at the 1.65, 1.45 and 1.30 day HRTs. However, during operation at an HRT of 1.18 days, the effluent $\mathrm{COD}_{\mathrm{VFA}}$ gradually increased, reaching a value of $3.3 \mathrm{~g} \mathrm{COD}_{\mathrm{VFA}} \mathrm{L}^{-1}$ after three days of data collection. The reactor operation was stopped; it was clear that the process limit had been reached because the biomass in the reactor was not capable of processing all of the incoming organic matter in the feed. This HRT can be considered the process performance limit under these conditions. Despite the decrease in efficiency for the lowest HRT, there was a significant correlation between the OLR and the ORR $(\mathrm{p}<0.05)$. The correlation between the OLR and the ORR during this period is shown in Fig. 3a, where it can be observed that the ORR increased with the OLR until the highest OLR (i.e., the shortest HRT), when the ORR slightly decreased. A very strong Pearson correlation between both parameters $(\mathrm{p}<0.001)$ would be observed if the last value (HRT of 1.18 days) were not taken into account.

As with the ORR, a significant correlation $(\mathrm{p}<0.05)$ was also found between the OLR 
and the volumetric methane production rate. In Fig. 3b, the methane yield and the methane content in biogas for this period are shown. The UASB yielded $5.6 \pm 0.8 \mathrm{~m}^{3}$ $\mathrm{CH}_{4} \mathrm{~m}^{-3} \mathrm{~d}^{-1}$ at a 2.2 day HRT. This rate increased progressively with decreasing HRT, reaching its highest value at a 1.3 day HRT, $9.5 \pm 0.5 \mathrm{~m}^{3} \mathrm{CH}_{4} \mathrm{~m}^{-3} \mathrm{~d}^{-1}$. For the shortest HRT applied, the methane yield slightly decreased (as with the ORR) down to $9.3 \pm 0.1$ $\mathrm{m}^{3} \mathrm{CH}_{4} \mathrm{~m}^{-3} \mathrm{~d}^{-1}$. Specific methane yields remained within the range of $0.33-0.34 \mathrm{~L} \mathrm{CH}_{4}$ $\mathrm{g}^{-1}$ COD for all of the HRTs except for 1.18 days, when it dropped down to $0.31 \mathrm{~L} \mathrm{CH}_{4}$

$\mathrm{g}^{-1}$ COD. With regards to the methane content in the biogas, there was no clear correlation with the OLR. The highest value was found at a 2.2 day HRT $(59.4 \pm 2.5 \%$ $\left.\mathrm{CH}_{4}\right)$, and the lowest value was found at a 1.45 day $\operatorname{HRT}\left(53.8 \pm 1.5 \% \mathrm{CH}_{4}\right)$. These data provide evidence that the decrease in methane content in biogas with an increasing OLR during the first period (at a constant HRT) was caused by the higher CW content in the feed (i.e., different organic compounds) rather than the higher OLR applied and the higher volumetric methane production rates.

\subsection{Biomass washout throughout the experimental period}

The external settler placed in the UASB reactor discharge had two functions: providing a clarified final effluent free of suspended solids and avoiding obstructions in the effluent recycle pipe. At the same time, the settler allowed collecting data about the amount of solids washed out during the UASB operation. In Figure 4, the amount of VSS collected from the settler for each condition is depicted.

As Fig. 4a shows, during stage 1, the biomass washout increased as the CW fraction in the feed also increased. This trend changed when the CW:SFCLF was 55:45. This observation can be attributed to the fact that the solids with the worst settling properties 
were washed out during the previous conditions, especially from CW:SFCLF ratios 35:65 to 50:50. During this period, $211.1 \mathrm{~g}$ of VSS were washed out. Critical biomass washout was experienced when the CW:SFCLF ratio was 85:15. Not only the biomass washout of the UASB reactor but also the blockage of the gas collector and effluent discharge pipe as reported previously forced a stop of the reactor operation. During stage 1, $523 \mathrm{~g}$ of VSS were collected from the settler. In spite of the biomass loss by washout, the UASB performance did not change because biomass growth replaced the washed-out biomass. During stage 2 (Fig. 4b), biomass washout was not very noticeable, which indicates that the previous biomass washout could be caused by the increasing CW content in the feed rather than the increasing biogas production rates. In this regard, Kalyuzhnyi et al. [22] related the good sludge settling properties in a UASB treating raw cheese whey up to an OLR of $28.5 \mathrm{~kg} \mathrm{COD} \mathrm{m}^{-3} \mathrm{~d}^{-1}$. Significant washout occurred when the OLR reached $29.2 \mathrm{~kg}$ COD m $\mathrm{m}^{-3} \mathrm{~d}^{-1}$. These authors reported low upflow velocity, gradual increase in the OLR and low acetate in the reactor medium as the reasons for successful formation of well-settling granules.

When the operation was concluded, the UASB reactor was emptied to determine the amount and the VSS content of the anaerobic biomass. The result was that $3860 \mathrm{~g}$ of biomass with $66.3 \mathrm{~g} \mathrm{VSS} \mathrm{kg}^{-1}$ remained in the UASB reactor (256 g VSS). Taking into account the maximum organic removal rate obtained (27.2 g COD removed $^{-1} \mathrm{~d}^{-1}$ - stage 2, HRT 1.3 days), the activity of biomass present in the reactor can be calculated according to the following equation:

$$
A=\frac{O R R\left(g \text { COD }_{\text {removed }} L^{-1} d^{-1}\right) \cdot \operatorname{Vol}_{\text {UASB }}(L)}{\operatorname{VSS} \text { in } \operatorname{UASB}(g)}
$$

From this equation, the activity of biomass at the end of the experiment was calculated resulting in $0.85 \mathrm{~g} \mathrm{COD} \mathrm{g}^{-1} \mathrm{VSS} \mathrm{d}^{-1}$. 
Based on the final amount of VSS remaining in the UASB reactor (256 g VSS) and the amount of VSS washed-out during the second stage (data from Fig. 4b), the solids retention time (SRT) of the UASB treatment process during the second stage has been estimated to be higher than 200 days according to the following equation:

$$
S R T=\frac{\text { VSS in UASB }(g)}{\text { Flow of VSS washed out }\left(g \cdot d^{-1}\right)}
$$

Such value for the SRT parameter is a very high value that would require periodic solids purging but it must be noted that because this study was focused on the effects of the CW fraction and the OLR on the biomass wash-out, solids were not periodically purged during UASB operation. In an industrial application, a final destination should be found for the excess solids washed-out or purged. Additional equipment should be installed for handling and storing excess of solids. Attending to chemical characterization (TS=90.0 $\mathrm{g} \mathrm{kg}^{-1}$, VS=66.3 $\mathrm{g} \mathrm{kg}^{-1}$, TKN-N=5.4 $\mathrm{g} \mathrm{kg}^{-1}, \mathrm{P}_{\mathrm{T}}=3.9 \mathrm{~g} \mathrm{~kg}^{-1}$ ), drying and composting may be an effective management option to improve the suitability and acceptability of these solids for use on agricultural land.

\subsection{Comparison with anaerobic digestion and co-digestion processes for cheese whey} and animal manure.

A comparison between the results from the present work with other previous works dealing with the anaerobic digestion of cheese whey and the anaerobic co-digestion of cheese whey and animal manure is given in Table 4. To our knowledge, this is the first study of cheese whey co-digested with a liquid fraction of dairy manure in a one-stage UASB reactor. In comparison with anaerobic co-digestion of cheese whey and animal manure in CSTR systems, the utilization of the liquid fraction as co-substrate allowed processing the mixture in a UASB reactor. In addition, this method permitted stable 
operation with a lower HRT (as low as 1.3 days) and higher CW:manure ratios (up to 75:25), resulting in a higher OLR (up to $28.7 \mathrm{~kg} \mathrm{COD} \mathrm{m}^{-3} \mathrm{~d}^{-1}$ ) and much higher volumetric biogas production rates (up to $16.6 \mathrm{~m}^{3} \mathrm{~m}^{-3} \mathrm{~d}^{-1}$ ). The high biodegradability and the low suspended solids content of both substrates employed is the reason for these differences.

Compared with previous anaerobic treatment systems reported for cheese whey, lower HRTs were tested, but some of those required a two-stage system, adding chemicals for $\mathrm{pH}$ or trace element control. Similar results to those of the current work in terms of process performance were reported by Kalyuzhnyi et al. [22], who were able to successfully treat cheese whey in a one-phase UASB reactor at a similar OLR. Chemical bicarbonate addition was required for the start-up of the reactor. However, these authors did not report data about biogas and methane production values. In this regard, it must be noted that higher biogas and methane production rates could be achieved with a better manure management strategy with the aim to avoid the aging of manure and its dilution with rain water. In this work, manure was taken from a partially uncovered manure pit where it was stored for several weeks. The optimal strategy would consist of separating the manure as soon as it was produced to avoid dilution and aging. In a previous work by the authors [36], manure was taken from the cow house, and separation processes were performed at lab scale. In that work, the SFCLF had $\mathrm{COD}_{\mathrm{T}}$ and $\mathrm{COD}_{\mathrm{VFA}}$ values of 14.3 and $10.2 \mathrm{~g} \mathrm{~L}^{-1}$, which are, respectively $59 \%$ and 73\% higher than those of the SFCLF in the present work. Therefore, higher methane potentials of the SFCLF and the resulting feed mixture could be obtained.

\section{Conclusions}


The present work has demonstrated that the anaerobic co-digestion of cheese whey and liquid fraction of dairy manure is feasible in a one-stage UASB process without external alkalinity and nutrient supplementation by means of effluent recirculation. An external settler is required to ensure a final effluent free of suspended solids and to avoid obstructions in the effluent recycle pipe. The proposed process allows much lower HRTs than those for conventional CSTR systems for the co-digestion of cheese whey with manure slurries, with the advantage of a considerable size reduction of the reactor. Moreover, stability problems caused by the lack of alkalinity in the CW are solved. The system demonstrated stable operation with $75 \% \mathrm{CW}$ in the mixture feed at an HRT of 2.2 days. A maximum OLR of $28.7 \mathrm{~kg} \mathrm{COD} \mathrm{m}^{-3} \mathrm{~d}^{-1}$ was reached with $60 \% \mathrm{CW}$ in the feed mixture under an HRT of 1.3 days, with 95.1\% COD removal and a stable volumetric methane production rate of $9.5 \mathrm{~m}^{3} \mathrm{CH}_{4} \mathrm{~m}^{-3} \mathrm{~d}^{-1}$. This new high-load codigestion method proposed can be an environmental solution for the polluting effluent of cheese making factories and intensive livestock farming.

\section{Acknowledgements}

The authors would like to thank the Ministry of Science and Innovation for financially supporting this research under contract CTM2011-28042. Co-funded with FEDER funds. 


\section{REFERENCES}

[1] A. Prazeres, F. Carvalho, J. Rivas, Cheese whey management: a review, J. Environ. Manage. 110 (2012) 48-68.

[2] S. Kaminarides, K. Nestoratos, T. Massouras, Effect of added milk and cream on the physicochemical, rheological and volatile compounds of Greek whey cheeses, Small Ruminant Res. 113 (2013) 446453.

[3] A.J. Mawson, Bioconversions for whey utilization and waste abatement, Bioresour Technol. 47 (1994) 195-203.

[4] P. Guimarães, J. Teixeira, L. Domingues, Fermentation of lactose to bio-ethanol by yeasts as part of integrated solutions for the valorisation of cheese whey, Biotechnol. Adv. 28 (2010) 375-384.

[5] A. Vamvakaki, I. Kandarakis, S. Kaminarides, M. Komaitis, S. Papanikolaou, Cheese whey as a renewable substrate for microbial lipid and biomass production by Zygomycetes, Eng. Life Sci. 10 (2010) 348-360.

[6] A.E. Ghaly, M.A. Kamal, Submerged yeast fermentation of acid cheese whey for protein production and pollution potential reduction, Water Res. 38 (2004) 631-644.

[7] F. Kargi, S. Ozmihci, Utilization of cheese whey powder (CWP) for ethanol fermentations: effects of operating parameters, Enzyme Microb. Technol. 38 (2006) 711-718.

[8] M.I. González Siso, The biotechnological utilization of cheese whey: a review, Bioresour. Technol. 57 (1996) 1-11.

[9] S.S. Marwaha, J.F. Kennedy, Review: whey pollution problem and potential utilization, Int. J. Food Sci. Technol. 23 (1988) 323-336.

[10] F. Carvalho, A.R. Prazeres, J. Rivas, Cheese whey wastewater: Characterization and treatment, Sci. Total Environ. 445-446 (2013) 385-396.

[11] A. Saddoud, I. Hassaïri, S. Sayadi, Anaerobic membrane reactor with phase separation for the treatment of cheese whey, Bioresour. Technol. 98 (2007) 2102-2108.

[12] A. Villar, [Status and prospects of cheese whey management in Cantabria], Agrarian Research and Training Center of Cantabria, 2005. Available from:

http://www.cifacantabria.com/Documentacioncifa/download.php?sess=0\&parent=18\&expand=1\&order= $\underline{\text { name\&binary=1\&id=13, }}$ Spanish.

[13] J. Gelegenis, D. Georgakakis, I. Angelidak, V. Marris, Optimization of biogas production by co- 
digesting whey with diluted poultry manure, Renew. Energy 32 (2007) 2147-2160.

[14] T. Spachos, A. Stamatis, Thermal analysis and optimization of an anaerobic treatment system of whey, Renew. Energy 36 (2011) 2097-2105.

[15] A.E. Ghaly, A comparative study of anaerobic digestion of acid cheese whey and dairy manure in a two-stage reactor, Bioresour. Technol. 58 (1996) 61-72.

[16] F. Malaspina, C.M. Cellamare, L. Stante, A. Tilche, Anaerobic treatment of cheese whey with a downflow-upflow hybrid reactor, Bioresour. Technol. 55 (1996) 131-139.

[17] G. Mockaitis, S.M. Ratusznei, J.A.D. Rodrigues, M. Zaiat, E. Foresti, Anaerobic whey treatment by a stirred sequencing batch reactor (ASBR): effects of organic loading and supplemented alkalinity, J. Environ. Manage. 79 (2006) 198-206.

[18] J.Q. Yan, P.H. Liao, K.V. Lo, Methane production from cheese whey, Biomass 17 (1988) 185-202.

[19] K.V. Lo, P.H. Liao, Two-stage anaerobic digestion of cheese whey, Biomass 10 (1986) 319-322.

[20] M. Asif Latif, R. Ghufran, Z.A. Wahid, A. Ahmad, Integrated application of upflow anaerobic sludge blanket reactor for the treatment of wastewaters, Water Res. 45 (2011) 4683-4699.

[21] P.A. García, J.L. Rico, F. Fdz-Polanco, Anaerobic treatment of cheese whey in a two-phase UASB reactor, Environ. Technol. 12 (1991) 355-362.

[22] S.V. Kalyuzhnyi, E. Pérez, J. Rodriguez, Anaerobic treatment of high-strength cheese-whey wastewaters in laboratory and pilot UASB-reactors, Bioresour. Technol. 60 (1997) 59-65.

[23] T. Ergüder, U. Tezel, E. Güven, G.N. Demirer, Anaerobic biotransformation and methane generation potential of cheese whey in batch and UASB reactors, Waste Manage. 21 (2001) 643-650.

[24] V. Diamantis, A. Kapagiannidis, S. Ntougias, V. Tataki, P. Melidis, A. Aivasidis, Two-stage CSTRUASB digestion enables superior and alkali addition-free cheese whey treatment, Biochem. Eng. J. 84 (2014) 45-52.

[25] M. Passeggi, I. López, L. Borzacconi, Modified UASB reactor for dairy industry wastewater: performance indicators and comparison with the traditional approach, J Cleaner Production 26 (2013) 90-94.

[26] C. Kelly, M. Switzenbaum, Anaerobic treatment: Temperature and nutrient effects, Agric. Wastes 10 (1984) 135-154.

[27] B. Kavacik, B. Topaloglu, Biogas production from codigestion of a mixture of cheese whey and dairy manure, Biomass Bioenergy 34 (2010) 1321-1329. 
[28] E. Comino, V.A. Riggio, M. Rosso, Biogas production by anaerobic co-digestion of cattle slurry and cheese whey, Bioresour. Technol. 114 (2012) 46-53.

[29] L. Bertin, S. Grilli, A. Spagni, F. Fava, Innovative two-stage anaerobic process for effective codigestion of cheese whey and cattle manure, Bioresour. Technol. 128 (2013) 779-783.

[30] J.B. Holm-Nielsen, T. Al Seadi, P. Oleskowicz-Popiel, The future of anaerobic digestion and biogas utilization, Bioresour. Technol. 100 (2009) 5478-5484.

[31] J.L. Rico, H. García, C. Rico, I. Tejero, Characterisation of solid and liquid fractions of dairy manure with regard to their component distribution and methane production, Bioresour. Technol. 98 (2007) 971-979.

[32] C. Rico, J.L. Rico, I. Tejero, N. Muñoz, B. Gómez, Anaerobic digestion of the liquid fraction of dairy manure in pilot plant for biogas production: Residual methane yield of digestate, Waste Manage. 31 (2011) 2167-2173

[33] G. Lettinga, L.W. Hulshoff Pol, UASB process design for various types of wastewaters, Water Sci. Technol. 24 (1991) 87-107.

[34] G.K. Anderson, G. Yang, Determination of Bicarbonate and Total Volatile Acid Concentration in Anaerobic Digesters Using a Simple Titration, Water Environ. Res. 64 (1992) 53-59.

[35] APHA, Standard methods for the examination of water and wastewater (20 ${ }^{\text {th }}$ ed.), American Public Health Association, Washington DC, USA, 1998.

[36] C. Rico, H. García, J.L. Rico, Physical-anaerobic-chemical process for treatment of dairy cattle manure, Bioresour. Technol. 102 (2011) 2143-2150. 


\section{Figure Captions}

Fig. 1- Experimental set-up scheme.

Fig. 2- Performance data of the UASB reactor at constant HRT (2.2 days) and a increasing $\mathrm{CW}$ content in the feed. a) Correlation between the OLR and the ORR. b) Volumetric methane production rate and methane content in biogas. The values showed are the mean values \pm SD of five duplicate samples after steady state conditions were reached.

Fig. 3- Performance data of the UASB reactor at a constant CW:SFCLF ratio content in the feed and a decreasing HRT. a) Correlation between the OLR and the ORR. b) Volumetric methane production rate and methane content in biogas. The values showed are the mean values \pm SD of five duplicate samples after steady state conditions were reached.

Fig. 4- Biomass losses in the UASB reactor throughout the whole experimental period.

a) Operation at a constant HRT (2.2 days) and an increasing CW content in the feed. b) Operation at a constant CW:SFCLF feed ratio and a decreasing HRT. 